\title{
Growth rates of tomato seedlings and seasonal radiation*
}

D. Klapwijk and P. J. A. L. de Lint

Glasshouse Crops Research and Experiment Station, Naaldwijk, the Netherlands

\section{Summary}

During the years 1970 to 1972,34 batches of tomatoes were sown at regular intervals. Until the plants flowered, their fresh weight was determined once or twice a week. The data were used to calculate daily growth percentages and the number of days required by the plants to develop from 0.1 to $10 \mathrm{~g}$ fresh weight per plant. For each of the growing periods the radiation totals and the average radiation per day were calculated. The data obtained were related to each other and compared with the information obtained by other research workers.

The growing methods used resulted in substantially higher growth rates and higher light efficiency than were known from previous work carried out under natural light conditions (Brouwer, 1973). However, the same very high relative growth rates have been recorded more recently in growth chambers with artificial irradiation (Hurd \& Thornley, 1974).

Nevertheless, there are still unknown factors which have caused a disproportionate reduction in the light efficiency of many batches during the summer period. Further investigations into these aspects are necessary.

\section{Introduction}

Plant growth, and especially the rate of growth of young tomato seedlings, varies with the time of year. This well-known phenomenon has been described and quantified by a number of research workers (Blackman et al., 1955; Bunt, 1972; Cooper, 1966, 1967; Hegarty, 1973; Hodgson, 1967; Voldeng \& Blackman, 1963). Apart from the effects of temperatures, the amount of daily radiation is generally regarded as the direct cause of growth variations.

The data are presented as annual growth curves and occasionally as light efficiency curves. There are very large variations in the absolute growth rates recorded by different workers (Warren Wilson, 1966).

The data in this publication are of a similar nature, although the aim has been to achieve maximum growth rates in all seasons. A plentiful supply of water and automated fertilization proved to be crucial for this. The temperature regime was also found to be very important.

Thirty-four sowings were made between 1970 and the end of 1972. In many

* Publikatie van het Proefstation voor de Groenten- en Fruitteelt onder Glas te Naaldwijk No 211. 
cases the treatment giving the quickest growth was chosen from an experiment as the basis for the annual cropping programme. The starts of the treatments were also selected in such a way that an evenly distributed annual cycle was obtained (see also de Lint \& Klapwijk, 1973, 1974).

Samples were taken from the different batches, twice a week in summer and once a week in winter. This means that five to eight observations were made for each sowing from the moment of emergence until the first truss came into flower. The data obtained were used for plotting growth curves. Those sections of the growth curves representing the development of the plants from $0.1 \mathrm{~g}$ to $10 \mathrm{~g}$ fresh weight per plant were analysed further and related to the amounts of light received.

The information obtained is discussed and compared with the data obtained by other research workers.

\section{Materials and methods}

Tomatoes of the cv 'Moneymaker' were sown directly into 3-litre black plastic pots filled with peat compost. The compost consisted of a mixture of $85 \%$ sphagnum peat and $15 \%$ black sedge peat. To each cubic metre of the mixture were added $5 \mathrm{~kg}$ of ground dolomite lime stone, $1.5 \mathrm{~kg}$ compound fertilizer (14-14-14), $0.5 \mathrm{~kg}$ Sporumix PG (25\% MgO, $0.3 \% \mathrm{Cu}, 0.1 \% \mathrm{~B}, 0.6 \% \mathrm{Mo}$ and $0.5 \% \mathrm{Mn}$ ), and $25 \mathrm{~g} \mathrm{Fe} 138$ (chelated iron).

After emergence, the seedlings were thinned to 8 to 10 per pot, leaving a uniform stand of plants in each pot. When the plants developed they were thinned again to avoid overcrowding. The thinnings were used as samples for the determination of fresh weights. Other growth characteristics were not measured as these can be deduced adequately from the fresh weight figures (de Lint \& Klapwijk, 1974).

The plastic pots were placed on glasshouse staging in $2 \mathrm{~cm}$ of liquid feed in which they remained for the duration of the experiment. Root development was satisfactory even in the layer of peat which was submerged in the nutrient solution (de Lint \& Klapwijk, 1974). The nutrient solution was prepared from a compound fertilizer (13-5-13-5) and its concentration was automatically controlled at about 1 atm osmotic pressure by resistance measurement. The $\mathrm{pH}$ and electric conductivity of the nutrient solution were determined in the laboratory once a week. The solution in the glasshouse staging was replaced twice a day in summer and once a day in winter.

The glasshouse used for the experiments was a Venlo type block of average height, metal clad, with a bay width of $4.8 \mathrm{~m}$ and two-sided half-length ridge ventilation. Light transmission was $70 \%$ maximum.

Between May and September 1970 and 1971, the average maximum day temperature was 35 to $37^{\circ} \mathrm{C}$. In 1972 , the thermostat was moved from between the plants to an insulated, aspirated screen. As a result the summer temperature dropped to 30 to $32{ }^{\circ} \mathrm{C}$. During the winter months the temperatures gradually dropped to an average maximum day temperature of 22 to $24{ }^{\circ} \mathrm{C}$. The average minimum night temperature was 20 to $22^{\circ} \mathrm{C}$ between March and October and gradually decreased in winter to 14 to $16^{\circ} \mathrm{C}$. No $\mathrm{CO}_{2}$ enrichment was applied. 


\section{GROWTH RATES OF TOMATO SEEDLINGS AND SEASONAL RADIATION}

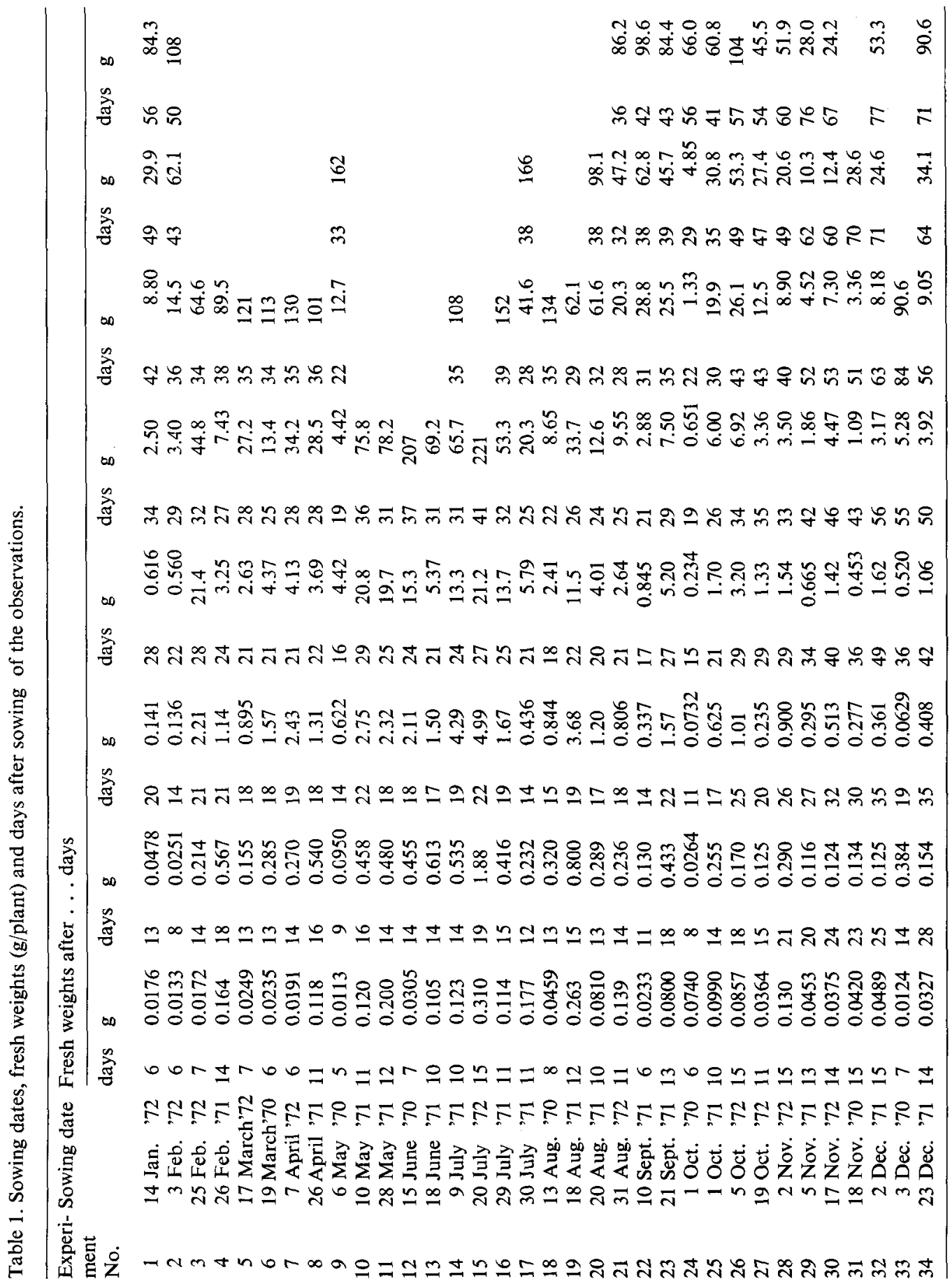

Neth. J. agric. Sci. 23 (1975) 
Table 2. Relationship between fresh weight ranging from $0.1-10 \mathrm{~g}$ per plant $(\mathrm{y})$ and time $(\mathrm{x})$ according to the equation $\log \mathrm{y}=\mathrm{ax}+\mathrm{b}$.

\begin{tabular}{|c|c|c|c|}
\hline $\begin{array}{l}\text { Experiment } \\
\text { No }\end{array}$ & $\begin{array}{l}\text { Regression } \\
\text { coefficient } \\
\text { (a) }\end{array}$ & $\begin{array}{l}\text { Constant } \\
\text { (b) }\end{array}$ & $\begin{array}{l}\text { Correlation } \\
\text { coefficient } \\
\text { (r) }\end{array}$ \\
\hline 1 & 0.0805 & -2.4349 & 0.9982 \\
\hline 2 & 0.0939 & -2.2270 & 0.9975 \\
\hline 3 & 0.1317 & -2.4683 & 0.9961 \\
\hline 4 & 0.1287 & -2.5772 & 0.9988 \\
\hline 5 & 0.1497 & -2.7441 & 0.9999 \\
\hline 6 & 0.1409 & -2.3592 & 0.9987 \\
\hline 7 & 0.1478 & -2.5388 & 0.9932 \\
\hline 8 & 0.1397 & -2.4645 & 0.9988 \\
\hline 9 & 0.1683 & -2.5860 & 0.9986 \\
\hline 10 & 0.1250 & -2.3129 & 0.9998 \\
\hline 11 & 0.1517 & -2.4544 & 0.9968 \\
\hline 12 & 0.1515 & -2.4379 & 0.9992 \\
\hline 13 & 0.1310 & -2.1260 & 0.9934 \\
\hline 14 & 0.1301 & -2.0716 & 0.9894 \\
\hline 15 & 0.1512 & -2.6906 & 0.9932 \\
\hline 16 & 0.1303 & -2.3065 & 0.9935 \\
\hline 17 & 0.1444 & -2.3470 & 0.9986 \\
\hline 18 & 0.1577 & -2.4970 & 0.9957 \\
\hline 19 & 0.1425 & -2.2090 & 0.9944 \\
\hline 20 & 0.1222 & -1.9838 & 0.9871 \\
\hline 21 & 0.1276 & -2.3134 & 0.9961 \\
\hline 22 & 0.1010 & -1.8425 & 0.9886 \\
\hline 23 & 0.0950 & -1.9434 & 0.9920 \\
\hline 24 & 0.1012 & -2.1720 & 0.9944 \\
\hline 25 & 0.0944 & -1.8166 & 0.9860 \\
\hline 26 & 0.0787 & -1.9778 & 0.9849 \\
\hline 27 & 0.0689 & -1.9165 & 0.9960 \\
\hline 28 & 0.0593 & -1.6181 & 0.9829 \\
\hline 29 & 0.0426 & -1.6552 & 0.9925 \\
\hline 30 & 0.0500 & -1.9002 & 0.9859 \\
\hline 31 & 0.0504 & -2.0826 & 0.9983 \\
\hline 32 & 0.0503 & -2.2164 & 0.9979 \\
\hline 33 & 0.0488 & -2.0757 & 0.9978 \\
\hline 34 & 0.0651 & -2.6665 & 0.9994 \\
\hline
\end{tabular}

\section{Results}

If the fresh weight figures obtained from the sample determinations are plotted on a logarithmic axis against the time, practically straight lines are obtained. The growth lines only level out with fresh weight figures in excess of about $100 \mathrm{~g}$.

A certain rate of growth which may be expressed as a daily growth percentage (RGR) is therefore maintained by the young plants for a long time. During the time when the young plant develops from 0.1 to $10 \mathrm{~g}$ fresh weight, the daily growth percentage is constant. 


\section{GROWTH RATES OF TOMATO SEEDLINGS AND SEASONAL RADIATION}

Table 3. Data on growth of young tomato plants (gathered from Table 1) and on radiation.

\begin{tabular}{|c|c|c|c|c|c|c|c|c|}
\hline \multirow{2}{*}{$\begin{array}{l}\text { Experi- } \\
\text { ment } \\
\text { No }\end{array}$} & \multicolumn{4}{|c|}{$\begin{array}{l}\text { Dates at which fresh weights } \\
\text { were reached }\end{array}$} & \multirow{2}{*}{\multicolumn{2}{|c|}{$\begin{array}{l}\text { Number RGR } \\
\text { of days (\% per } \\
0.1-10 \mathrm{~g} \text { day) }\end{array}$}} & \multirow{2}{*}{$\begin{array}{l}\text { Total } \\
\text { radiation } \\
0.1-10 \mathrm{~g} \\
\left(\mathrm{cal} \mathrm{cm}^{-2}\right)\end{array}$} & \multirow{2}{*}{$\begin{array}{l}\text { Radiation } \\
\text { per day } \\
\left(\text { cal } \mathrm{cm}^{-2}\right)\end{array}$} \\
\hline & 0.1 & & $1.0 \mathrm{~g}$ & $10 \mathrm{~g}$ & & & & \\
\hline 1 & & Feb. & 14 Feb. & 26 Feb. & 25 & 20.4 & 2433 & 97 \\
\hline 2 & 16 & Feb. & 27 Feb. & 8 March & 21 & 24.1 & 2720 & 130 \\
\hline 3 & 7 & March & 15 March & 22 March & 15 & 35.4 & 3713 & 248 \\
\hline 4 & 10 & March & 18 March & 26 March & 16 & 34.2 & 2980 & 186 \\
\hline 5 & 29 & March & 6 April & 11 April & 13 & 41.2 & 3330 & 256 \\
\hline 6 & 29 & March & 5 April & 12 April & 14 & 38.3 & 3407 & 243 \\
\hline 7 & 17 & April & 24 April & 1 May & 14 & 40.5 & 4835 & 345 \\
\hline 8 & 6 & May & 14 May & 21 May & 15 & 37.9 & 7050 & 470 \\
\hline 9 & 15 & May & 21 May & 27 May & 12 & 47.3 & 4972 & 414 \\
\hline 10 & 21 & May & 29 May & 6 June & 16 & 33.3 & 6828 & 427 \\
\hline 11 & 7 & June & 14 June & 20 June & 13 & 41.8 & 4133 & 318 \\
\hline 12 & 24 & June & 1 July & 8 July & 14 & 41.7 & 5280 & 377 \\
\hline 13 & 27 & June & 5 July & 12 July & 15 & 35.2 & 8687 & 579 \\
\hline 14 & & July & 24 July & 2 Aug. & 16 & 34.9 & 6320 & 395 \\
\hline 15 & 31 & July & 6 Aug. & 13 Aug. & 13 & 41.6 & 4933 & 379 \\
\hline 16 & & Aug. & 15 Aug. & 23 Aug. & 15 & 35.0 & 4455 & 297 \\
\hline 17 & & Aug. & 15 Aug. & 22 Aug. & 14 & 39.4 & 4156 & 297 \\
\hline 18 & 22 & Aug. & 29 Aug. & 4 Sept. & 13 & 43.8 & 5462 & 415 \\
\hline 19 & 26 & Aug. & 3 Sept. & 10 Sept. & 15 & 38.8 & 5127 & 342 \\
\hline 20 & 28 & Aug. & 5 Sept. & 13 Sept. & 16 & 32.5 & 5547 & 347 \\
\hline 21 & 10 & Sept. & 18 Sept. & 26 Sept. & 16 & 34.1 & 3966 & 248 \\
\hline 22 & 18 & Sept. & 28 Sept. & 8 Oct. & 20 & 26.2 & 5032 & 252 \\
\hline 23 & & Oct. & 12 Oct. & 22 Oct. & 21 & 24.4 & 4261 & 203 \\
\hline 24 & 13 & Oct. & 23 Oct. & 1 Nov. & 19 & 26.2 & 2352 & 124 \\
\hline 25 & 10 & Oct. & 20 Oct. & 30 Oct. & 20 & 24.3 & 3172 & 159 \\
\hline 26 & 17 & Oct. & 30 Oct. & 12 Nov. & 26 & 19.9 & 2668 & 103 \\
\hline 27 & & Nov. & 16 Nov. & 30 Nov. & 29 & 17.2 & 1850 & 64 \\
\hline 28 & 12 & Nov. & 29 Nov. & 16 Dec. & 34 & 14.6 & 1902 & 56 \\
\hline 29 & 20 & Nov. & 14 Dec. & 6 Jan. & 47 & 10.3 & 1739 & 37 \\
\hline 30 & & Dec. & $25 \mathrm{Dec}$ & 14 Jan. & 40 & 12.2 & 1788 & 45 \\
\hline 31 & 9 & Dec. & 29 Dec. & 18 Jan. & 40 & 12.3 & 1919 & 48 \\
\hline 32 & 26 & Dec. & 15 Jan. & 4 Feb. & 40 & 12.3 & 2053 & 51 \\
\hline 33 & 25 & Dec. & 15 Jan. & 4 Feb. & 41 & 11.9 & 2338 & 57 \\
\hline 34 & 18 & Jan. & 2 Feb. & 17 Feb. & 30 & 16.2 & 2529 & 84 \\
\hline
\end{tabular}

The basic data of 34 batches sown from 1970 until the end of 1972 are shown in Table 1. The accuracy of the determinations within each sowing is given in Table 2.

These data have been used to calculate the dates on which the plants should have reached a weight of 0.1 and $10 \mathrm{~g}$, the number of days between these dates and the average daily growth percentage (Table 3 ).

The total and average amounts of daily radiation were determined for these periods with figures obtained from the meteorological reports of the Royal Dutch Meteorological Institute at De Bilt and of the Research Station at Naaldwijk. 


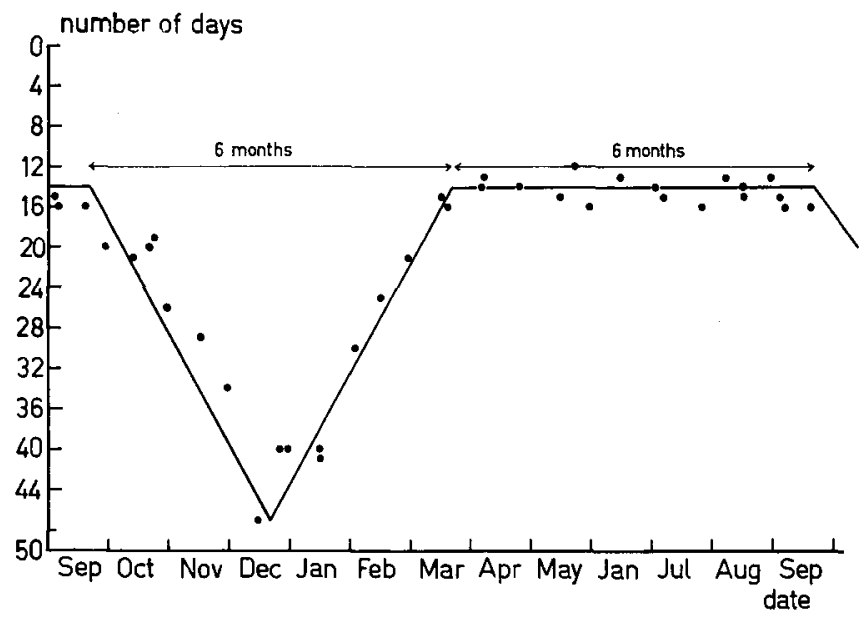

Fig. 1. Tomatoes, 34 sowings in 1970 to 1972 . For each sowing the number of days in which the plants developed from 0.1 to $10 \mathrm{~g}$ fresh weight plotted against the dates on which the plants reached a fresh weight of $1 \mathrm{~g}$ per plant.

The relationship of the data in Table 3 is shown in Fig. 1 to 4 .

A comparison of the data in Fig. 1 and 2 shows that the length of the growing period from 0.1 to $10 \mathrm{~g}$ fresh weight per plant is determined by the amount of radiation in winter only. From the beginning of March until after mid-September, the length of the growing period remains constant to a high degree. This seems to confirm the observations by Calvert (1964) who found that in winter the rate of growth is determined largely by the amount of photosynthetic light available, but

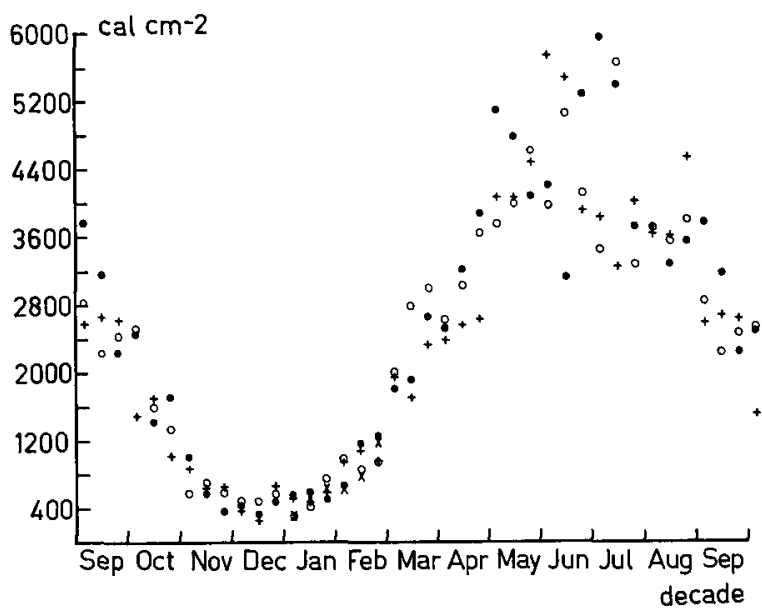

Fig. 2. The sums of the total radiation per decade ( $\mathrm{cal} \mathrm{cm-2}^{-2}$ ) at Naaldwijk $(+1970,-1971, \circ 1972$, $x$ 1973). Until 1 November, 1970, the figures were obtained from De Bilt and after this date from Naaldwijk. $1 \mathrm{cal}=4.2 \mathrm{~J}$. 


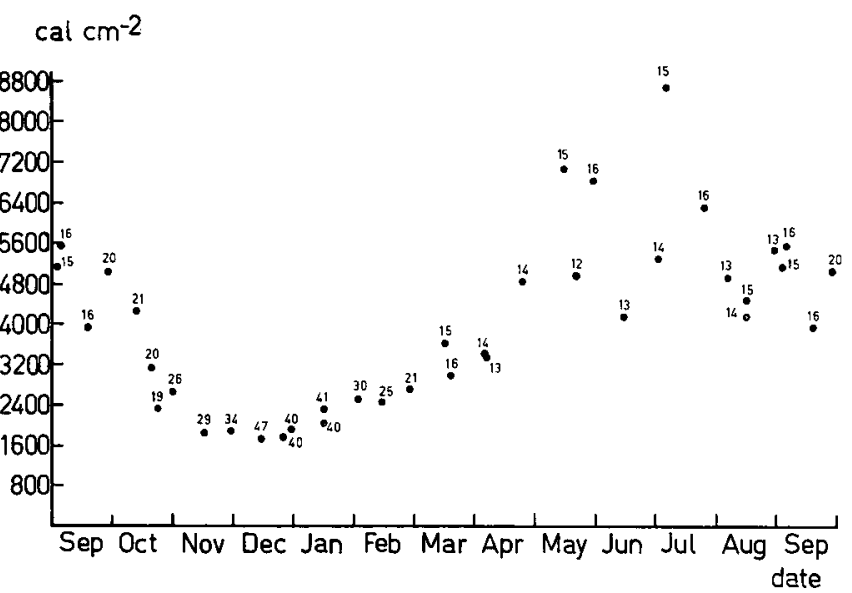

Fig. 3. Tomatoes, 34 sowings, 1970 to 1972 . The sums of the total radiation (cal $\mathrm{cm}^{-2}$ ) for each sowing during the period in which the plants increased in fresh weight from 0.1 to $10 \mathrm{~g}$ per plant plotted against the dates on which the plants reached a fresh weight of $1 \mathrm{~g}$ per plant. The figures near the points denote the number of days of the growing period of each sowing.

that in summer the young tomato plant is saturated with light and growth is limited by other factors. Fig. 3 shows this relationship in greater detail.

The position of the points in Fig. 3 shows that there was a very wide variation in the amount of radiation which reached the plants of the different batches in summer. In winter the points show a more regular pattern. Fig. 3 shows that a minimum of about $1.700 \mathrm{cal} \mathrm{cm}^{-2}$ overall radiation was received during the period when the plant developed from 0.1 to $10 \mathrm{~g}$ fresh weight. At the other extreme there is a batch which showed the same development with about $8.600 \mathrm{cal} \mathrm{cm}^{-2}$ radiation.

Fig. 4A shows that high radiation totals are not always accompanied by high growth rates. On the other hand, very high growth rates may be achieved with only moderate radiation levels. However, from the 11 points which have been circled and which represent favourable growth and light efficiency, it may be concluded that there is increasing growth up to the highest light values. A saturation level does not appear to have been reached, not even with the highest levels of summer radiation. Why the other 23 batches had a lower growth rate in spite of adequate light is clearly a point for further investigation (temperatures, $\mathrm{CO}_{2}$ concentration, rooting medium).

It could be suggested that sowings which were subjected to very high radiation totals were harmed by excessive radiation. However, this is deceptive. Slow-growing batches will have received radiation over a longer period, so radiation need not have been of exceptionally high intensity, even if the total radiation figure was high. This is also shown by the change in the positions of the points in Fig. 4A and 4B. 

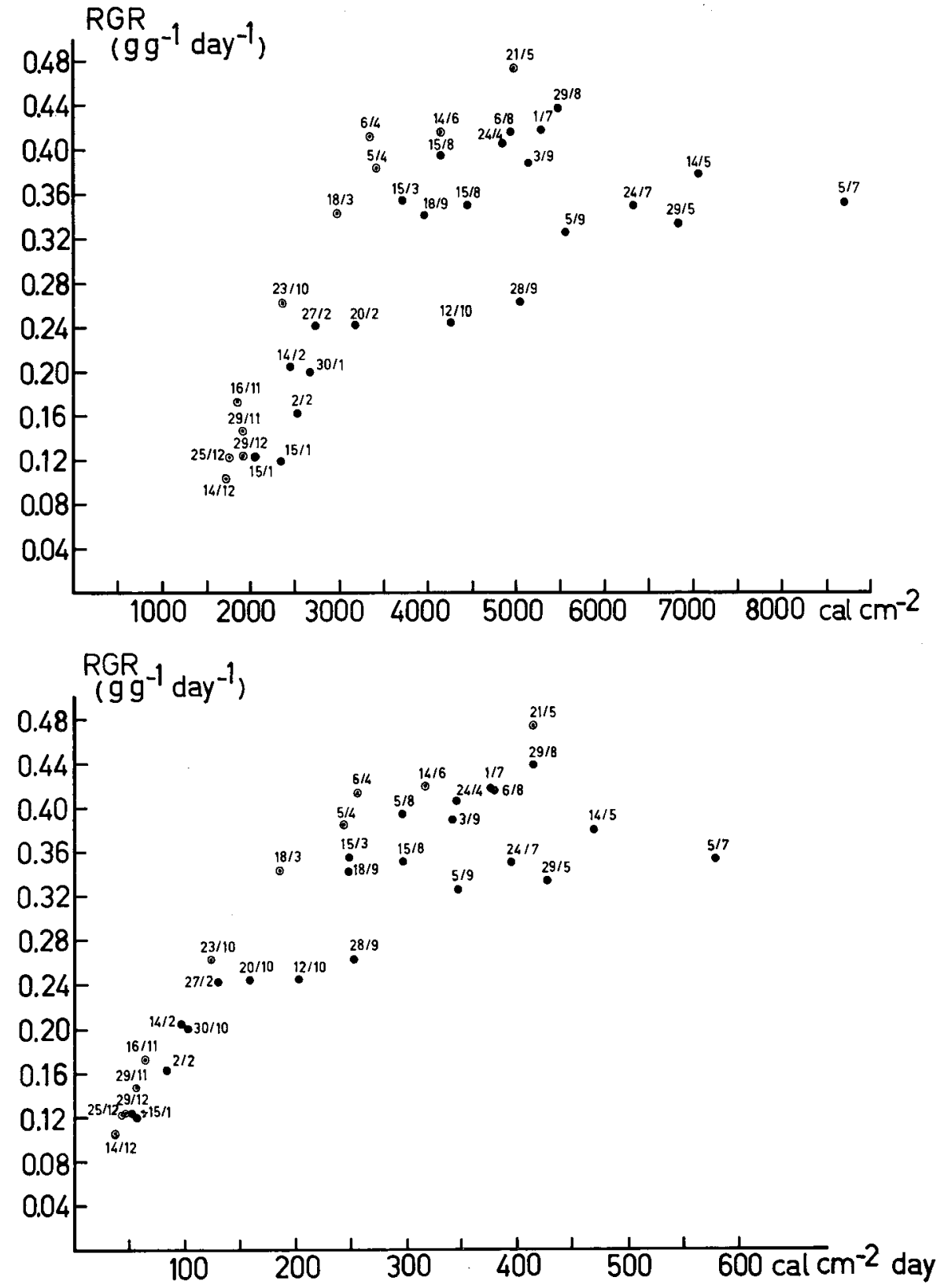

Fig. 4. Tomatoes, 34 sowings, 1970 to 1972 . RGR ( $\mathrm{g} \mathrm{g}^{-1} \mathrm{day}^{-1}$ ) plotted against total radiation. $4 \mathrm{~A}$ (top): Sum of the total radiation during the period in which the plants of a sowing increased in fresh weight from 0.1 to $10 \mathrm{~g}$ per plant.

4B (bottom): Average total radiation per day during the growing period of each sowing.

The figures near the points in Fig. $4 \mathrm{~A}$ and $4 \mathrm{~B}$ denote the dates on which the plants reached $1 \mathrm{~g}$ per plant in fresh weight. The circled points denote the eleven sowings which showed the best growth over the radiation range. The eleven points in Fig. 4B were used in Fig. 5. 


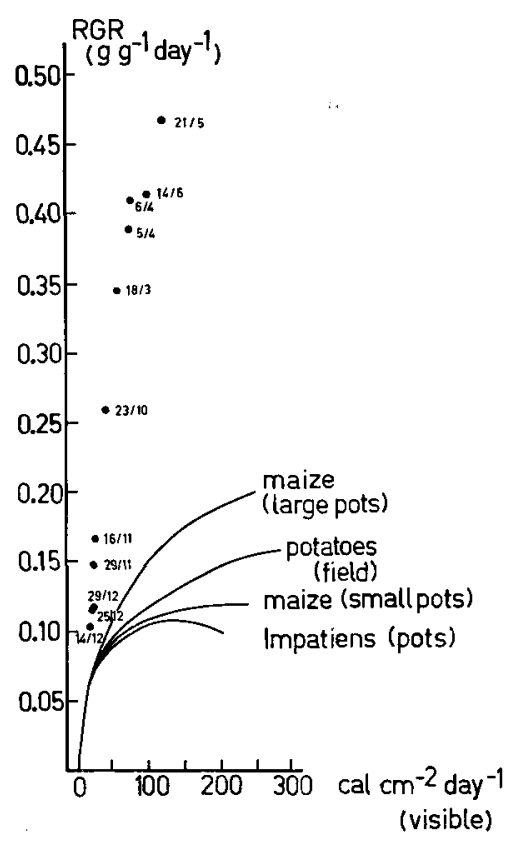

Fig. 5. $\left.R \mathrm{R}^{\left(\mathrm{g}^{-1}\right.} \mathrm{g}^{-1} \mathrm{y}^{-1}\right)$ against visible radiation (cal $\mathrm{cm}^{-2}$ day-1). The eleven points with an indication of the dates were taken from Fig. 4B. The other graphs were taken from a compilation by Brouwer (1973).

\section{Discussion}

Brouwer (1973) has compiled daily growth percentages $\left(\mathrm{g} \mathrm{g}^{-1} \mathrm{day}^{-1}\right.$ ) in relation to daily visible radiation. The radiation data from the meteorological stations used in this publication were obtained with solarimeters, and they should therefore be halved to make them comparable with Brouwer's 'visible' radiation values. In addition, it is estimated that the glasshouse structure intercepted at least $30 \%$ of the radiation.

Fig. 5 shows some of Brouwer's curves to which have been added the data of the 11 sowings circled in Fig. $4 \mathrm{~b}$ and plotted against the corrected radiation figures.

The relative growth rates of the 34 tomato batches in this publication differ in two respects from those shown in Fig. 4 of Brouwer's paper. Firstly, the light efficiency of these tomato plants is higher than that reported in all previous publications. Secondly, the maximum relative growth rate obtained is also much higher: Brouwer, maize, maximum $20 \%$; in this report, Fig. 4, up to $47.3 \%$.

However, the highest values (the points in Fig. 5) are not normal in this material. Particularly in summer various sowings showed appreciably lower rates of light utilisation than proved possible with others. The factors responsible for this could not be traced.

Warren Wilson (1966) reported very high photosynthetic activities of sunflowers in Australia. His figures were almost twice as high as the previously known data. It is not possible to make a straight comparison between our figures and those obtained by Warren Wilson, but an estimation shows that the figures obtained by 
Brouwer with maize are about as high as those from Australia.

The data obtained by Hurd \& Thornley (1974) however, obtained in growth chambers, are directly comparable. Their plants also achieved about $45 \%$ maximum relative growth rates. It is therefore feasible to achieve very high growth rates in glasshouses with natural light as well as in growth chambers with artificial irradiation. These growth rates are of the same order as those achieved with duckweed (Lemna minor), viz $35 \%$ (Hodgson, 1970) and $68 \%$ (J. Rombach, pers. commun., 1974).

\section{Acknowledgment}

We thank Miss Brenda van Beek for her assistance in accurately recording most of the data used in this paper.

\section{References}

Blackman, G. E., J. N. Black \& A. W. Kemp, 1955. Physiological and ecological studies in the analysis of plant environment. $X$. An analysis of the effects of seasonal variation in daylight and temperature on the growth of Helianthus annuus in the vegetative phase. Ann. Bot. 19: 527-548.

Brouwer, R., 1973. Dynamics of plant performance. Acta Hort. 32: 31-49.

Bunt, A. C., 1972. Effect of season on the carnation (Dianthus caryophyllus L.). I. Growth rate. J. hort. Sci. 47: 467-477.

Calvert, A., 1964. Growth and flowering of the tomato in relation to natural light conditions. J. hort. Sci. 39: 182-193.

Cooper, A. J., 1966. Seasonal changes in net assimilation and leaf growth of young tomato plants. Acta Hort. 4: 76-78.

Cooper, A. J., 1967. Effects of shading and time of the year on net assimilation rates of young glasshouse tomato plants. Ann. appl. Biol. 59: 85-90.

Hegarty, T. W., 1973. Effects of total solar radiation and temperature on vegetative growth in the east of Scotland. J. appl. Ecol. 10: 145-156.

Hodgson, G. L., 1967. Physiological and ecological studies in the analysis of plant environment. XIII. A comparison of the effects of seasonal variations in light energy and temperature on the growth of Helianthus annuus and Vicia faba in the vegetative phase. Ann. Bot. 31: 291-308.

Hodgson, G. L., 1970. Effects of temperature on the growth and development of Lemna minor under conditions of natural daylight. Ann. Bot. 34: 365-381.

Hurd, R. G. \& J. H. M. Thornley, 1974. An analysis of the growth of young tomato plants in water culture at different light integrals and $\mathrm{CO}_{2}$ concentrations. I. Physiological aspects. Ann. Bot. 38: 375-388.

Klapwijk, D. \& P. J. A. L. de Lint, 1974. Fresh weight and flowering of tomato plants as influenced by container type and watering conditions. Acta Hort. 39: 237-247.

Lint, P. J. A. L. de \& D. Klapwijk, 1973. Observations on growth and development rates of tomato seedlings. Acta Hort. 32: 161-169.

Lint, P. J. A. L. de \& D. Klapwijk, 1974. Correlations between plant weight characteristics of young tomato plants. Acta Hort. 39: 249-262.

Voldeng, H. D. \& G. E. Blackman, 1963. The influences of seasonal changes in solar radiation and air temperature on the growth in the early vegetative phase of Zea mays. Ann. Bot. 37: 553-563.

Warren Wilson, J., 1966. High net assimilation rates of sunflower plants in an arid climate. Ann. Bot. 30: 745-751. 